\title{
Models for non-heme oxidation enzymes
}

\author{
D.H.R. BARTON and D.K. TAYLOR \\ Texas A\&M University, Department of Chemistry, College Station, TX 77843-3255; USA
}

\begin{abstract}
The Gif systems for the selective functionalization of saturated hydrocarbons based on the reactions of superoxide with $\mathrm{Fe}^{\mathrm{II}}$ and of hydrogen peroxide with Fe $\mathrm{F}^{\text {III }}$ are described. [1] Both systems are relatively efficient, but not nearly so efficient as the electrochemical system developed in collaboration with Prof. G. Balavoine and Dr. Aurore Gref (Université de Paris-Sud--Orsay, France). [2] All systems afford mainly ketones. This is an unusual selectivity which implies a non-radical mechanism. It has been proven for the Fe $\mathrm{e}^{\text {III }}$ $\mathrm{H}_{2} \mathrm{O}_{2}$ system that the activation of the $\mathrm{Fe}$ III is independent of the formation of ketone which comes from oxygen. The intermediate for the ketone is a hydroperoxide (derived from oxygen). [3] Recent mechanistic studies are reported.
\end{abstract}

\section{INTRODUCTION}

There is universal acceptance that the selective functionalization of saturated hydrocarbons is a research challenge of major proportions. Although paraffins are, as their name implies, usually considered to be inert, Nature has solved the problem of their functionalization using complexes of iron and, to a lesser extent of copper. The iron complexes are either heme based, as in the ubiquitous $\mathbf{P}_{\mathbf{4 5 0}}$ enzymes, or non-heme based, as in the vitally important proline-4-hydroxylase and in the fascinating enzyme, methane monooxygenase. These enzymes contain one $\mathrm{Fe}$ III , or two $\mathrm{Fe}^{\mathrm{III}}$ atoms bridged by an oxo bridge, respectively. Although the protein in these enzymes is responsible for their chemo- and stereo-selectivity, the fundamental activation of the iron should be seen also in appropriate models. Models of $\mathrm{P}_{450}$ enzymes have been known for decades and the work of J.T. Groves is particularly noteworthy in this respect. Models of non-heme iron enzymes are much less familiar and, until our publications on Gif type Chemistry, not efficacious. [5]

\section{USE OF SUPEROXIDE AND OF HYDROGEN PEROXIDE}

Our work started with the assumption that when, 3 billion years ago, the blue-green algae started to make oxygen, a unicellular form of life started to concert the oxidation of iron with the oxidation of saturated hydrocarbons. It is agreed that after 1 billion years of life under reductive conditions, the world was full of saturated hydrocarbons, $\mathrm{Fe}^{\mathrm{II}}$ compounds and metallic iron, as well as, an abundance of hydrogen sulfide, since life was using the reduction of sulfate to sulfide as an energy source.

So our first experiment to test our hypothesis was the oxidation of adamantane in pyridine with some acetic acid in the presence of iron powder, hydrogen sulfide and oxygen. Surprisingly, a major amount of adamantanone was formed and there was only minor formation of the tertiary alcohol. Later, we obtained the same results when we replaced the iron powder with zinc powder and added a catalytic amount of an Fe $\mathrm{e}^{\mathrm{II}}$ salt. This showed the unusual power of the iron species formed to make ketones as principal products.

During systematic studies on adamantane oxidation, we examined the effect of reducing oxygen pressure. We were surprised to find that lowering the oxygen pressure increased the selectivity for adamantanone formation. We defined selectivity as $C^{2} / C^{3}$ where $C^{2}$ is total product at the secondary position and $C^{3}$ is total product at the tertiary position. Both are normally expressed as mmol. At the secondary position, only ketone and alcohol are formed. At the tertiary position, reduction of oxygen pressure caused formation of $t$-adamantyl groups attached to the 2- and 4-positions of pyridine, as well as, production of $t$-adamantanol. When all sec. and tert. products were taken into consideration, then $C^{2} / \mathrm{C}^{3}$ was about 1.0 and was pressure invariant. In contrast, the $C^{2} / C^{3}$ for oxygen radical reactions is about 0.1 . By application of Ockam's razor, we concluded that an intermediate was formed at both sec. and tert. positions. We postulated that this was formed by insertion of an $\mathrm{Fe}^{\mathrm{V}}$ oxenoid species into the carbon-hydrogen bond. At the secondary position, the iron-carbon bond was stable, but at the tertiary position, the weaker bond fragmented into radicals which coupled with pyridine in the ordinary way. All the appropriate blank experiments were carried out to show that secondary radicals, had they been formed at the lower oxygen pressures, would have been captured by the solvent pyridine. [6] Subsequently, potassium superoxide was reacted with $\mathrm{Fe}^{\mathrm{II}}$ under argon and shown to give an iron species that also gave an adamantane selectivity of about $\mathbf{1 . 0}$. 
Similarly, Fe IIl and $\mathrm{H}_{2} \mathrm{O}_{2}$ showed the same behavior. We can summarize all the results in the following way:

$$
\begin{aligned}
& \mathrm{Fe}+{ }^{\circ} \mathrm{O}_{2}^{-}+\mathrm{H}^{\oplus} \equiv \mathrm{Fe} I I I+\mathrm{H}_{2} \mathrm{O}_{2} \longrightarrow \mathrm{Felll}-\mathrm{O}-\mathrm{OH} \\
& \text { III } \mathrm{Fe}_{\mathrm{O}} C_{\mathrm{OH}} \longrightarrow \mathrm{Fe}=\mathrm{O} \text { (the oxenoid species) } \\
& \mathrm{FeV}=\mathrm{O}+\stackrel{1}{\mathrm{C}} \mathrm{H}_{2} \longrightarrow \mathrm{FeV}-\stackrel{1}{\mathrm{C}} \mathrm{H}
\end{aligned}
$$

The $\mathrm{H}_{2} \mathrm{O}_{2}$ system is very convenient to use and, since it is homogeneous, it lends itself to $\mathrm{C}^{13}$ N.M.R. studies. Using singly labeled cyclohexane, we could show that an intermediate was formed between cyclohexane and cyclohexanone. By comparison with an authentic specimen and by isolation, this was shown to be cyclohexyl hydroperoxide. The reaction, at room temperature, had a half-life of about 2 hours and so was easy to follow by N.M.R.

Further evidence for an intermediate hydroperoxide was found in $\mathrm{Zn}^{0}-\mathrm{Fe}^{\mathrm{Il}}$-superoxide experiments when $\mathrm{PPh}_{3}$ was added before the formation of the superoxide. This did not change the total amount of oxidation (ketone + alcohol), but did dramatically change the ketone to alcohol ratio in favor of alcohol. Hydroperoxides are, of course, rapidly reduced by $\mathrm{PPh}_{3}$ to alcohols. Furthermore when trimethyl phosphite is used instead of $\mathrm{PPh}_{3}$, the products of the reaction are phosphate and ketone. [7] Trimethyl phosphite is a reagent which reduces hydroperoxides at once to alcohols. This new trimethyl phosphite reaction can be understood better when we ask the question how is the hydroperoxide formed?

Using $\mathrm{Fe} \mathrm{III}^{\mathrm{II}}$ and $\mathrm{H}_{2} \mathrm{O}_{2}$, this question can be answered. If we accept that $\mathrm{Fe}$ III is oxidized to the $\mathrm{Fe}^{\mathrm{V}}$ oxenoid, then we can also understand how this is reduced back again to $\mathrm{Fe}^{\mathrm{III}}$ and $\mathrm{O}_{2}$ by a second molecule of $\mathrm{H}_{2} \mathrm{O}_{2}$. Using $18 \mathrm{O}_{2}$ labeled oxygen, we can show that the oxygen that appears in the hydroperoxide is indeed formed from oxygen and not from hydrogen peroxide. Does this mean that we have a conventional autoxidation process? The trimethyl phosphite reaction mentioned above precludes this possibility. Hydroperoxyl and alkoxyl radicals are reduced very efficiently by trimethyl phosphite to furnish alkyl radicals. We have indeed confirmed that this is so under Gif conditions. Therefore, the reaction with trimethyl phosphite which forms phosphate (see above) precludes the intermediacy of a hydroperoxyl radical. We propose the mechanism shown in Scheme 1.

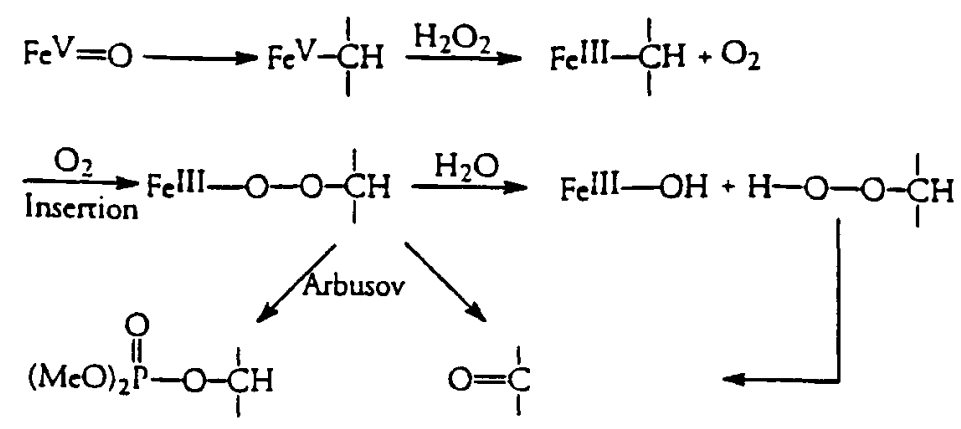

Scheme 1

The key step here is the insertion of oxygen into the $\mathrm{Fe}^{\mathrm{III}}$-carbon bond for which there is precedent in porphyrin chemistry. [3]

Further study of the $\mathrm{Fe}^{\mathrm{III}}-\mathrm{H}_{2} \mathrm{O}_{2}$ reaction showed that bromotrichloromethane and its congeners afford bromination instead of oxidation. The selectivity is the same as the oxidation reaction and does not follow a typical radical bromination pattern. [4] Scheme 2 shows a series of hydrocarbons and their relative reactivity

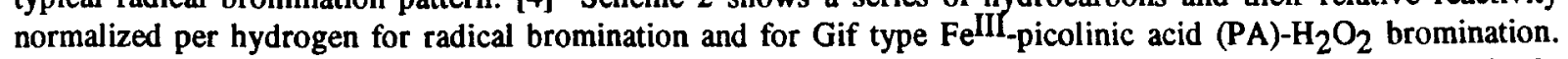
In each case, the $\mathrm{C}-\mathrm{H}$ bond reactivity in cyclohexane is set at 1.0. The two sets of numbers are completely different. Cyclohexane is the most active hydrocarbon in Gif bromination and the least active in radical bromination. The data were accumulated by competing the hydrocarbons mixed together in pairs. This avoids the possibility that radical chain reactions might be different in two separate experiments carried out under nominally the same conditions in different flasks. 
Radical Bromination

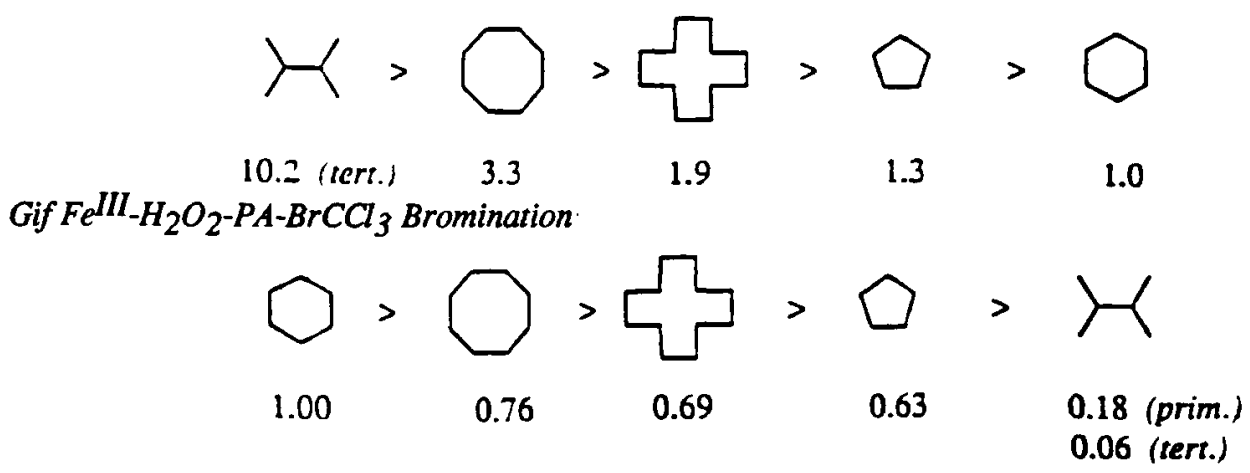

Scheme 2

The same conclusion could be drawn from a comparison of the relative reactivity of the brominating reagents in radical bromination and in Gif bromination. [4]

For relative rates of radical bromination with the reagents, a competition was set up between the reagents, one by one, and thiophenol. Cyclohexyl radicals were generated by photolysis of the cyclohexyl carboxylic ester of $\mathrm{N}$-hydroxy-2-thiopyridone so one measures the ratio cyclohexane (from the thiophenol hydrogen atom transfer) and cyclohexyl bromide from the reagent. For the Gif chemistry, competitive oxidation to cyclohexanone was compared to bromination using the Fe III $-\mathrm{PA}-\mathrm{H}_{2} \mathrm{O}_{2}$-brominating agent. In all cases of Gif bromination, the other product was $\mathrm{CO}_{2}$ and not the normal $\mathrm{Br}-\mathrm{X} \rightarrow \mathrm{H}-\mathrm{X}$ as seen in radical bromination chemistry. All the results show clearly that Gif bromination and radical bromination are completely different processes.

Another good test for radical bromination is bromination of cyclohexyl bromide. When radical bromination is involved, the trans-1,2-dibromide is the major product (Skell-Walling effect). Again with Gif bromination, completely different results are seen. [4]

Our new results for the radical bromination of cyclohexyl bromide are largely in agreement with the literature and completely different from the results of Gif bromination. A major equatorial preference is seen in that much more cis-1,3-dibromide (diequatorial) than trans (equatorial, axial) is formed, whereas for the 1,4dibromination, much more trans-(diequatorial) than cis-(equatorial, axial) dibromide is seen. Insertion of the $\mathrm{Fe}^{\mathrm{V}}$ oxenoid is subject to steric hindrance and hence equatorial insertion followed by ligand coupling of bromide with retention of configuration would be expected in agreement with the results.

Less extensive data (Scheme 3) are at present available for the oxidation of cycloalkanes to ketones. [8] The results are expressed per $\mathrm{C}-\mathrm{H}$ bond and cyclohexane is taken as 1.0. Again the hydrocarbons were competed against each other in pairs. The order is approximately the same as for the Fe $\mathrm{III}_{-}-\mathrm{PA}-\mathrm{H}_{2} \mathrm{O}_{2}$ bromination, but of course, the ligands are very different.

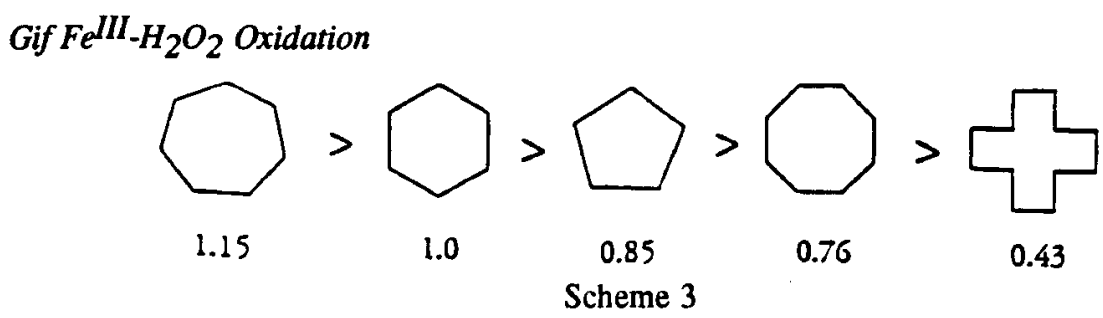

The oxidation of saturated hydrocarbons at the cathode of an electrochemical cell (Fell + superoxide) is a superior procedure from the viewpoint of electronic yield. An extensive study ${ }^{2}$ carried out in collaboration with Prof. G. Balavoine, Dr. Aurore Gref and other colleagues at the Universite de Paris-Sud gave results partially summarized in Table 1.

Table 1

\begin{tabular}{|c|c|c|}
\hline \multirow{2}{*}{ Hydrocarbon } & \multicolumn{2}{|c|}{ Electronic Yield \% } \\
\cline { 2 - 3 } & Cliemical & Electrochemical \\
\hline Methvicrclopentane & 3.6 & 20 \\
\hline cis-Decalin & 34 & 50 \\
\hline trans-Decalin & 16 & 42 \\
\hline Adamantane & 3 & 12 \\
\hline
\end{tabular}


The electronic yield represents the $\%$ of the electrons which come from the zinc in the $\mathrm{Zn}^{0}-\mathrm{Fe}^{\mathrm{II}}-\mathrm{O}_{2}$ system, or from the cathode which appear in the final product. The electrochemical system is far superior from this point of view and it is also more selective. The electrochemical system uses trifluoroacetic acid, instead of acetic acid. The protonation of the pyridine provides the cations necessary for the conductance of the current.

In any case, the selectivity of the electrochemical system confirms the preferential attack that we have seen on secondary positions during extensive studies on the oxidation of natural products.

The present position for the theory of Gif chemistry is summarized in Scheme 4.

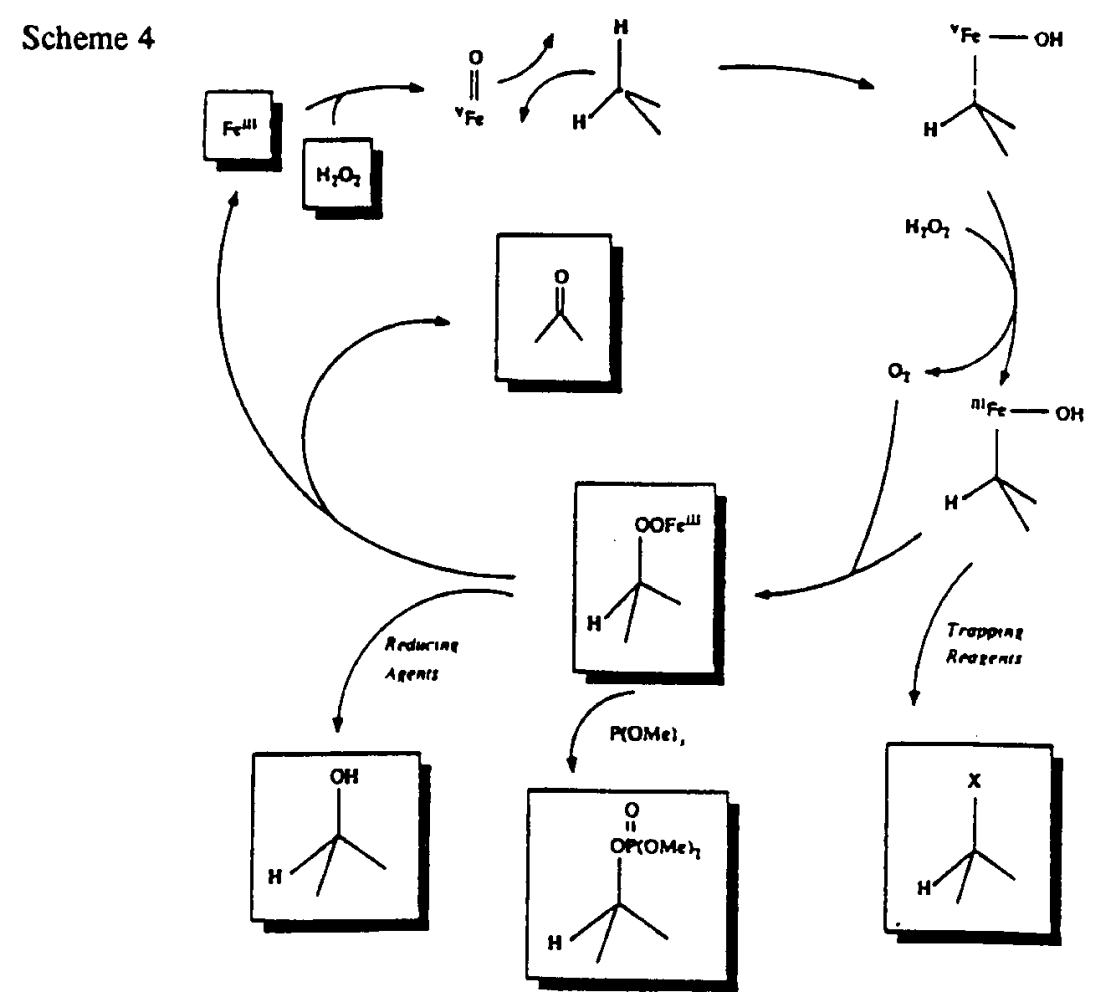

It is now clear that two intermediates can be discerned in Gif chemistry, A and B. B has been thoroughly characterized as the hydroperoxide which is the precursor of the ketone and of the alcohol. There is evidence (trimethyl phosphite effect) that the hydroperoxide is formed via a form bound to iron. The intermediate $A$ is not a carbon radical since it does not react with pyridine even when all the oxygen is removed by a vacuum. Its reactivity towards bromotrichloromethane is very different from standard radical bromination. The postulated iron-carbon bond is still the best hypothesis for $\mathbf{A}$.

It is established that the activation of the iron does lead to an attack on the hydrocarbon and that oxygen from gaseous oxygen is introduced in a second step. This contrasts to the theory of $\mathrm{P}_{450}$ oxidation where the activation of the iron leads to attack on the hydrocarbon and thence to hydroxylation. Recent work in our laboratory has confirmed experimentally this theory.

\section{USE OF t.-BUTYLHYDROPEROXIDE (TBHP)}

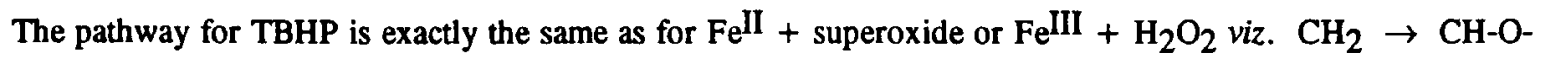
$\mathrm{OH} \rightarrow \mathrm{C}=\mathrm{O}$ (major) $+\mathrm{CHOH}$ (minor). The same reaction pathway was demonstrated for the solvent acetonitrile although here the alcohol is the main product. [9],[10], [11], [12]

When saturated hydrocarbons are oxidized with $\mathrm{Fe}^{\mathrm{III}}-\mathrm{H}_{2} \mathrm{O}_{2}$ or $\mathrm{Fe}^{\mathrm{Illi}}-\mathrm{PA}-\mathrm{H}_{2} \mathrm{O}_{2}$ in the presence of chloride or azide ions, the corresponding chlorides or azides are not observed even in vacuo. However in TBHP oxidations at $60^{\circ} \mathrm{C}$, the use of $\mathrm{FeCl}_{3}$ and, in particular, the addition of chloride anion gave chloride formation in up to quantitative yield with respect to TBHP. Azide, thiocyanate and other anions also reacted smoothly.

We had interpreted these anionic coupling reactions as ligand coupling on an $\mathrm{Fe}^{\mathrm{V}}$ species to which a carbon and a (say) chloride are bonded. [11], [12], [13] This would furnish the observed chloride and FeIII.

Minisci and Fontana [14] have recently offered an alternative explanation in which an Fe II species ( of undefined origin) reacts with TBHP in the Fenton manner to generate a $t$.-butoxide radical, which then reacts with the hydrocarbon to make a carbon radical, which then reacts with the anion attached to Fe $\mathrm{F}^{\mathrm{III}}$ and so makes the derivative and reforms $\mathrm{Fe}^{\mathrm{II}}$. In any case, we do have a very efficient method for turning saturated hydrocarbons into their monochloro derivatives. [15] 
Prof. D.T. Sawyer and his colleagues have made important contributions to Gif chemistry. In addition to optimization studies, they have confirmed that the $\mathrm{Fe}^{\mathrm{III}}-\mathrm{H}_{2} \mathrm{O}_{2}$ system produces ketones selectively. [16], [17], [18], [19]

Prof. U. Schuchardt and his colleagues [20], [21] have made a thorough study of the conversion of cyclohexane to cyclohexanone under various Gif systems. The reaction can be optimized to an excellent level of efficiency. We also note the related work by Prof. Patin. [22], [23]

\section{THE Fe $\mathrm{I}_{-F} \mathrm{e}^{I V}$ MANIFOLD. INTRODUCTION.}

As already alluded to, chlorides and bromides can be formed by $\mathrm{CCl}_{4}$ and $\mathrm{BrCCl}_{3}$ trapping respectively in the $\mathrm{Fe}^{\mathrm{III}}-\mathrm{H}_{2} \mathrm{O}_{2}$ system but are never seen by a reaction with chloride or bromide anions. [4] Formation of chloride is possible however if $\mathrm{PPh}_{3}$ is added to the $\mathrm{Fe}^{\mathrm{III}}-\mathrm{H}_{2} \mathrm{O}_{2}$ system containing chloride ion. [24] In contrast, chlorides are readily and efficiently formed $[11,25]$ by Fe ${ }^{\text {III }}$-tert-butyl hydroperoxide (TBHP) oxidation of saturated hydrocarbons at $60^{\circ} \mathrm{C}$ (half-live $\approx 110$ minutes) when chloride ion is present. Likewise azides, thiocyanates, cyanides and even nitro-compounds (from nitrite anion) are easily prepared. [12] We found finally that $\mathrm{Fe}^{\mathrm{II}}-\mathrm{H}_{2} \mathrm{O}_{2}$ is at the origin of chloride formation in the aforementioned systems. Hydroxyl radicals are not involved (traditional Fenton chemistry) while tert-butoxy radicals are at least in part responsible for hydrocarbon activation with TBHP in the presence of $\mathrm{Fe}^{\mathrm{II}}$.

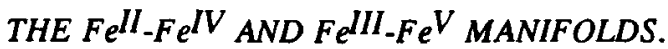

During recent systematic studies into the chloride formation from the $\mathrm{Fe}^{\mathrm{III}}-\mathrm{H}_{2} \mathrm{O}_{2}-\mathrm{PPh}_{3}$ system we had occasion to add ferrous chloride. This resulted in the immediate formation of large amounts of alkyl chloride. This therefore raised the question. was triphenyl phosphine reducing a $\mathrm{Fe}^{\mathrm{III}}$ complex to $\mathrm{Fe}^{\mathrm{II}}$ and does this valent state of iron give rise to the observed chloride? That such a reduction is possible was confirmed by titration experiments which showed that $\mathrm{Fe}^{\mathrm{III}} \mu$-oxo dimers (believed to be the initial species formed in solution) are transformed to $\mathrm{Fe}^{\mathrm{II}}$ and triphenyl phosphine oxide in the presence of $\mathrm{H}_{2} \mathrm{O}_{2}$. With these results in hand we then tumed our attention to the $\mathrm{Fe}^{\mathrm{II}}-\mathrm{Fe}^{\mathrm{IV}}$ manifold. There were also some heplful comments from Prof. F. Minisci (Milan)(vide supra).

The reactivity of adamantane towards the $\mathrm{Fe}^{\mathrm{II}}-\mathrm{H}_{2} \mathrm{O}_{2}$ and $\mathrm{Fe}^{\mathrm{II}}-\mathrm{TBHP}$ systems was studied. Addition of chloride ions to the $\mathrm{Fe}^{\mathrm{II}}-\mathrm{H}_{2} \mathrm{O}_{2}$ system not only significantly increases the amount of reaction but also results in a dramatic increase in the $\mathrm{C}^{2} / \mathrm{C}^{3}$ ratio. The activation of adamantane is thus catalyst dependant and suggests as such that the activation of the hydrocarbon cannot be due to formation of hydroxyl radicals (Fenton chemistry) as the $\mathrm{C}^{2} / \mathrm{C}^{3}$ ratio should remain constant. Support for carbon radicals in the $\mathrm{Fe}^{\mathrm{II}}$ system came from the following experiments. When $\mathrm{Fe}^{\mathrm{II}}\left(\mathrm{ClO}_{4}\right)_{2}$ and cyclohexane $(40 \mathrm{mmol})$ were used, $1.07 \mathrm{mmol}$ of chloride was formed. When Tempo $(5 \mathrm{mmol})$ was added, chloride formation was suppressed completely in favor of formation of $1.06 \mathrm{mmol}$ of cyclohexyl Tempo adduct. This suggests that the alkyl chloride is not formed via ligand coupling. Furthermore, the product distribution was indicative of carbon radical chemistry. The $3^{0}$. adamantyl radical being highly reactive, (pyramidal and "primary-like")[26] reacts preferentially with the solvent (protonated pyridine) while the $2^{0}$-adamantyl radical is of greater stability, (planar)[26] and reacts with the Fe ${ }^{I I I}$. $\mathrm{Cl}$ species to produce Fe $\mathrm{II}^{\mathrm{II}}$ and alkyl chloride. Such coupling is of course known. [27] The initial process must be $\mathrm{Fe}^{\mathrm{IV}}$ oxenoid insertion followed by iron-carbon bond radical fragmentation.

Additional evidence against the activation process being due to formation of hydroxyl radicals came when excess benzene was added to the reaction mixture. No phenol was produced. Likewise functionalization of toluene gave benzyl chloride and benzyl alcohol / acetate and no cresols. Also the formation of highly reactive hydroxyl radicals in traditional Fenton chemistry is reflected in $\mathrm{k}_{\mathrm{H}} / \mathrm{kD}=1.0$. [28] The $\mathrm{Fe}^{\mathrm{II}}-\mathrm{H}_{2} \mathrm{O}_{2}$ system described here is very fast $\left(\mathrm{T}_{1 / 2} \ll 30 \mathrm{sec}\right.$. at $\left.-20^{\circ} \mathrm{C}\right)$ and has $\mathrm{kH}_{\mathrm{H}} / \mathrm{kD}=2.1$ The latter is in agreement with an $\mathrm{Fe}^{\mathrm{IV}}$ oxenoid process, (as in related Gif systems[1]) as a preliminary to radical formation. Recent literature supports this conclusion. [29]

The $\mathrm{Fe}^{\mathrm{II}}$-TBHP system has completely different characteristics. (a) The reaction is slower $\left(\mathrm{T}_{1 / 2} \approx 3 \mathrm{~min}\right.$. at $-20^{\circ} \mathrm{C}$ ); (b) $\mathrm{k}_{\mathrm{H}} / \mathrm{k}_{\mathrm{D}}=8.0$; (c) the efficiency is higher while the $\mathrm{C}^{2} / \mathrm{C}^{3}$ ratio is lower (0.24-0.55). Although the formation of alkyl radicals could not be confirmed by trapping with Tempo, ( $\mathrm{Fe}^{\mathrm{II}}$ converts Tempo to the parent hydroxylamine on the Fe II - TBHP time scale), the product distributions are again indicative of the intermediacy of $2^{\circ}$ and $3^{\circ}$-adamantyl radicals. [26] When tert-butoxy radicals were generated at $40^{\circ} \mathrm{C}$ in pyridine by decomposition of pre-formed di-t-butylperoxalate [30] under argon in the presence of adamantane, all the adamantyl radicals were captured by pyridine with a $C^{2} / C^{3}$ selectivity of 0.28 . The same ratio was seen in the presence of oxygen.

The species responsible for alkane activation in the Fe ${ }^{I I}$-TBHP chlorination system was further identified by evaluating the relative reactivity of primary, secondary and tertiary $\mathrm{C}-\mathrm{H}$ bonds in this system by employing equal amounts of cyclohexane and 2,3-dimethylbutme at $0^{\circ} \mathrm{C}$. After statistical correction the relative reactivities 
were fnund to be: $1^{0}(0.03): 2^{\circ}(1.0): 3^{\circ}(2.9)$ in close agreement with those determined for genuine tertbutoxy radicals, i.e., $1^{\circ}(0.1): 2^{\circ}(1.0): 3^{\circ}(4.4)$ at $40^{\circ} \mathrm{C}$. [31] Our results along with those outlined by Minisci [14][15] clearly suggest that the activation of hydrocarbons by the Fell-TBHP system is a result of efficient formation of tert-butoxy radicals. The formation of chloride in the $\mathrm{Fe}^{\mathrm{III}}$-TBHP system can therefore be rationalized as resulting from the $\mathrm{Fe}^{\mathrm{II}}$-TBHP manifold. It was previously determined that the $\mathrm{C}^{2} / \mathrm{C}^{3}$ adamantane ratio in the $\mathrm{Fe}^{\mathrm{III}}$ experiments was 0.55 [11] along with $\mathrm{k}_{\mathrm{H}} / \mathrm{k}_{\mathrm{D}}=8.0$. Again these criteria are identical with the Fe $\mathrm{II}_{\text {II }} \mathrm{TBHP}$ experiments described herein. It is possible that the $\mathrm{Fe}^{\mathrm{II}}$-TBHP cycle is initiated by the reduction of $\mathrm{Fe}^{\mathrm{III}}$ to $\mathrm{Fe}^{\mathrm{II}}$ at $60^{\circ} \mathrm{C}$. This is, however, a minor reaction because of the slow rate of chloride formation.

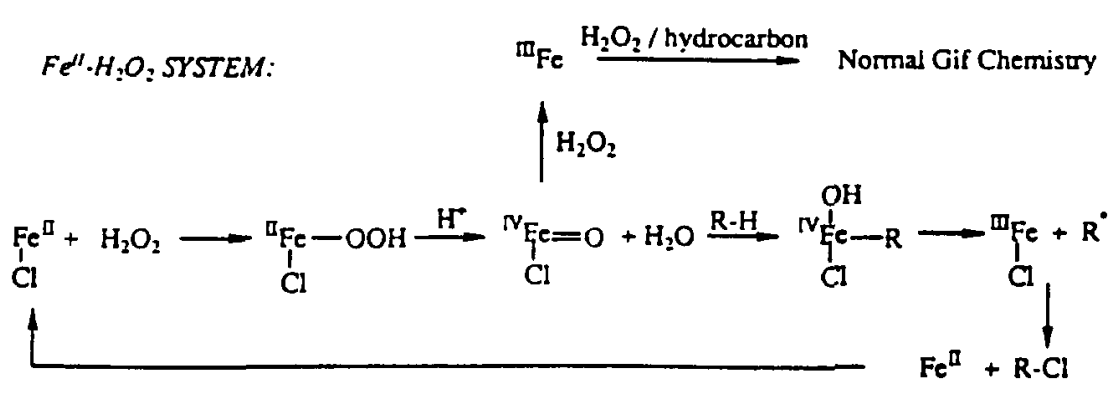

NOT FENTON CHEMISTRY:

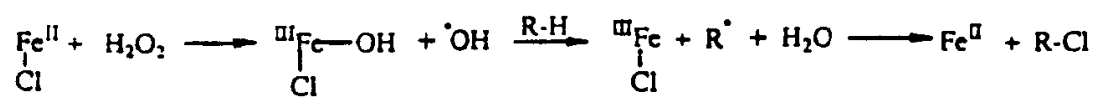

Fe'.TBHP SYSTEM:

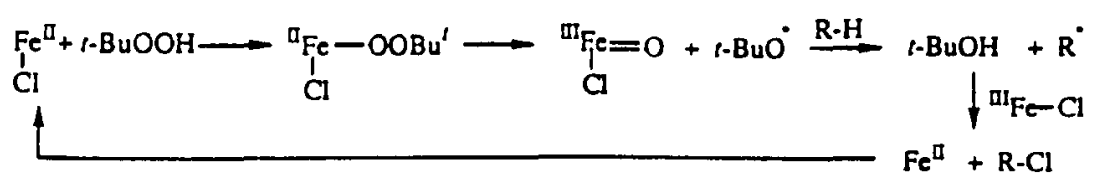

Scheme 5

The difference in chemical behaviour between the $\mathrm{Fe}^{\mathrm{II}}$ and $\mathrm{Fe}^{\mathrm{III}}-\mathrm{H}_{2} \mathrm{O}_{2}$ systems is highlighted by the following experiment. When cyclohexane and $\mathrm{Fe}^{\mathrm{II}}\left(\mathrm{ClO}_{4}\right)_{2}$ were treated with a 10-fold excess (with respect to $\left.\mathrm{Fe}^{\mathrm{II}}\right)$ of $\mathrm{H}_{2} \mathrm{O}_{2}\left(3 \mathrm{mmol}\right.$ every 15 minutes at $\left.0^{\circ} \mathrm{C}\right)$ in the presence of excess chloride ion, facile chloride formation was observed only while the system contained $\mathrm{Fe}^{\mathrm{II}}$ (titration). [32] However as soon as all the $\mathrm{Fe}^{\mathrm{II}}$ had been oxidised to $\mathrm{Fe}$ III (2 additions of $\mathrm{H}_{2} \mathrm{O}_{2}$ ), addition of further aliquots of $\mathrm{H}_{2} \mathrm{O}_{2}$ resulted in the relatively slow formation of ketone with very little additional chloride. The mechanism therefore changed from being radical $\left(\mathrm{Fe}^{\mathrm{II}}\right)$ to one involving the $\mathrm{Fe}^{\mathrm{III}}-\mathrm{Fe}^{\mathrm{V}}$ non-radical manifold. Comprehensive mechanistic details for the $\mathrm{Fe}^{\mathrm{II}}$ $\mathrm{H}_{2} \mathrm{O}_{2}$ system have revealed further that two catalytic cycles are operative in the $\mathrm{Fe}^{\mathrm{II}}-\mathrm{H}_{2} \mathrm{O}_{2}$ system. The first cycle produces chloride via the reaction of an $\mathrm{Fe}^{\mathrm{IV}}$ oxenoid with the hydrocarbon followed by subsequent reaction of the alkyl radical with liganded chloride on $\mathrm{Fe}^{\mathrm{III}}$ reforming $\mathrm{Fe}^{\mathrm{II}}$. The stoichiometry of this cycle is 1:1:1 in $\mathrm{Fe}$ II, $\mathrm{H}_{2} \mathrm{O}_{2}$ and chloride formation. Slow addition of the $\mathrm{H}_{2} \mathrm{O}_{2}$ therefore affords quantitativly alkyl chloride and $\mathrm{Fe}^{\mathrm{II}}$. The fact that alkyl chloride can be obtained in quantitative efficiency with respect to $\mathrm{H}_{2} \mathrm{O}_{2}$ employed clearly rules out the possibility that hydroxyl radicals are involved in the activation process. The competing cycle results from the $\mathrm{Fe}^{\mathrm{IV}}$ oxenoid reacting further with $\mathrm{H}_{2} \mathrm{O}_{2}$ to produce quantitatively $\mathrm{Fe}^{\mathrm{III}}$. Further addition of $\mathrm{H}_{2} \mathrm{O}_{2}$ therefore leads to $\mathrm{Gif}$ oxidation chemistry with no chloride formation. From the above results we conclude that the mechanism of hydrocarbon activation and alkyl chloride formation in the $\mathrm{Fe}^{\mathrm{II}}-\mathrm{H}_{2} \mathrm{O}_{2}$ and $\mathrm{Fe}^{\mathrm{II}}-\mathrm{TBHP}$ systems is as depicted in Scheme 5 .

Finally, the addition of thiocyanate or azide ions to the $\mathrm{Fe}^{\mathrm{II}}-\mathrm{H}_{2} \mathrm{O}_{2}$ and TBHP systems also produced substantial quantities of monosubstituted derivatives and is believed to proceed in a similar manner. Such behavior is of course in sharp contrast with the traditional thinking for Fenton chemistry, i.e., the hydrocarbon is activated by hydroxyl radical abstraction. We consider that the results now reported are a proof that Gif Fe III$\mathrm{H}_{2} \mathrm{O}_{2}$ chemistry is not radical chemistry. 
ACKNOWLEDGMENTS. We thank all our colleagues cited in the various References for their contributions to this fascinating subject. We also thank Prof. Minisci for his helpful comments. This work was supported by Quest Intl. and by the Welch Foundation.

\section{REFERENCES}

1. Barton, D.H.R. and Doller, D. (1992) The Selective Functionalization of Saturated Hydrocarbons: Gif Chemistry, Acc. Chem. Res. 25, 504-512.

2. Balavoine, G., Barton, D.H.R., Boivin, J., Gref, A., Le Coupanec, P., Ozbalik, N., Pestana, J.A.X., and Riviére, H. (1988) Functionalisation of Saturated Hydrocarbons. Part X.1. A Comparative Study of Chemical and Electrochemical Processes (Gif and Gif-Orsay Systems) in Pyridine, in Acetone and in Pyridine-Co-Solvent Mixtures, Tetrahedron 44, 1091-1106.

3. Barton, D.H.R., Bévière, S.D., Chavasiri, W., Csuhai, E., Doller, D., and Liu, W.-G. (1992) The Functionalization of Saturated Hydrocarbons. Part 20. Alkyl Hydroperoxides: Reaction Intermediates in the Oxidation of Saturated Hydrocarbons by Gif-Type Reactions and Mechanistic Studies on Their Formation, $J$. Am. Chem. Soc. 114, 2147-2156.

4. Barton, D.H.R., Csuhai, E., and Doller, D. (1992) The Functionalization of Saturated Hydrocarbons. Part 23. Gif-type Bromination and Chlorination of Saturated Hydrocarbons: A Non-radical Reaction, Tetrahedron 48, 9195-9206.

5. Barton, D.H.R., Gastiger, M.J., and Motherwell, W.B. (1983) A New Procedure for the Oxidation of Saturated Hydrocarbons, J. Chem. Soc., Chem. Comm., 41-43.

6. Barton, D.H.R., Halley, F., Ozbalik, N., Schmitt, M., Young, E., and Balavoine, G. (1989) Functionalization of Saturated Hydrocarbons. 14. Further Studies on the Mechanism of Gif-Type Systems, J. Am. Chem. Soc. 111, 7144-7149.

7. Barton, D.H.R., Bévière, S.D., and Doller, D. (1991) An Unprecedented Chemical Transformation: the Oxidation of Alkanes to Alkyl Dimethyl Phosphates, Tetrahedron Lett. 32, 4671-4674.

8. Barton, D.H.R., Bévière, S.D., Chavasiri, W., Csuhai, E., and Doller, D. (1992) The Functionalization of Saturated Hydrocarbons. Part XXI. The Fe(III)-Catalyzed and the Cu(II)-Catalyzed Oxidation of Saturated Hydrocarbons by Hydrogen Peroxide: A Comparative Study, Tetrahedron 48, 2895-2910.

9. Barton, D.H.R., Bévière, S.D., Chavasiri, W., Doller, D., and Hu, B. (1992) The Fe(III)-Catalyzed Functionalization of Saturated Hydrocarbons by tert-Butyl Hydroperoxide: Mechanistic Studies on the Role of Dioxygen, Tetrahedron Lett. 33, 5473-5476.

10. Barton, D.H.R. and Chavasiri, W. (1994) The Functionalization of Saturated Hydrocarbons. Part 24. The Use of tert-Butyl Hydroperoxide: GoAgg ${ }^{\mathrm{V}}$ and GoAgg $\mathrm{V}$, Tetrahedron 50, 19-30.

11. Barton, D.H.R., Bévière, S.D., and Chavasiri, W. (1994) The Functionalization of Saturated Hydrocarbons. Part 25. Ionic Substitution Reactions in GoAgg IV Chemistry: The Formation of Carbon-Halogen Bonds, Tetrahedron 50, 31-46.

12. Barton, D.H.R. and Chavasiri, W. (1994) The Functionalization of Saturated Hydrocarbons. Part 26. Ionic Substitutiton Reactions in GoAgg IV Chemistry: The Construction of C-N, C-S and C-C Bonds, Tetrahedron 50, 47-60.

13. Barton, D.H.R. and Wang, T.-L. (1994) The Selective Functionalization of Saturated Hydrocarbons. Part 28. The Acitivation of Benzylic Methylene Groups Under GoAgg IV and GoAgg V Conditions, Tetrahedron 50, 1011-1032.

14. Minisci, F. and Fontana, F. (1994) Mechanism of the Gif-Barton Type Alkane Functionalization by Halide and Pseudohalide Ions, Tetrahedron Lett. 35, 1427-1430.

15. Minisci, F., Fontana, F., Araneo, S., Recupeno, F. (1994) in press: Tetrahedron Lett.

16. Sheu, C., Sobkowiak, A., Zhang, L., Ozbalik, N., Barton, D.H.R., and Sawyer, D.T. (1989) IronHydroperoxide Induced Phenylselenization of Hydrocarbons (Fenton Chemistry), J. Am. Chem. Soc. 111, 8030-8032.

17. Sheu, C., Richert, S.A., Cofré, P., Ross, B., Jr., Sobkowiak, A., Sawyer, D.T., and Kanofsky, J.R. (1990) Iron-Induced Activation of Hydrogen Peroxide for the Direct Ketonization of Methylenic Carbon [c- $\mathrm{C}_{6} \mathrm{H}_{12} \rightarrow$ $\left.c-\mathrm{C}_{6} \mathrm{H}_{10}(\mathrm{O})\right]$ and the Dioxygenation of Acetylenes and Arylolefins, J. Am. Chem. Soc. 112, 1936-1942.

18. Sheu, C. and Sawyer, D.T. (1990) Activation of Dioxygen by Bis[(2,6-carboxyl, carboxylato)pyridine]iron (II) for the Bromination (via $\mathrm{BrCCl}_{3}$ ) and the Monooxygenation (via PhNHNHPh) of Saturated Hydrocarbons: Reaction Mimic for the Methane Monooxygenase Proteins, J. Am. Chem. Soc. 112, 82128214. 
19. Tung, H.-C., Kang, C., and Sawyer, D.T. (1992) Nature of the Reactive Intermediates from the IronInduced Activation of Hydrogen Peroxide: Agents for the Ketonization of Methylenic Carbons, the Monooxygenation of Hydrocarbons, and the Dioxygenation of Arylolefins, J. Am. Chem. Soc. 114, 34453455.

20. Schuchardt, U., Carvalho, W.A., Spinacé, E.V. (1993) Why is it Interesting to Study Cyclohexane Oxidation?, Synlett, 713-718.

21. Schuchardt, U., Krähembühl, C.E.Z., and Carvalho, W.A. (1991) High Efficiency of the GoAggII system in the Oxidation of Cyclohexane with Hydrogen Peroxide Under an Inert Atmosphere, New. J. Chem. 15, 955958.

22. Briffaud, T., Larpent, C. and Patin, H. (1990) Catalytic Alkane Activations in Reverse Microemulsions Containing Iron Salts and Hydrogen Peroxide, J. Chem. Soc., Chem. Commun., 1193-1194.

23. Larpent, C. and Patin, H. (1992) Oxidation of alkanes with hydrogen peroxide catalyzed by iron salts or iron oxide colloids in reverse microemulsions, J. Mol. Catal. 72, 315-329.

24. Barton, D.H.R. and Bévière, S.D. (1993) The Effect of Triphenylphosphine in the GoAgg ${ }^{\mathrm{II}}$ System, Tetrahedron Lett. 34, 5689-5692.

25. Barton, D.H.R., Bévière, S.D., Chavasiri, W., Doller, D., and Hu, B. (1993) New Alkane Functionalization Reactions Based on Gif-Type Chmeistry in the Presence of Alkali Metal Salts, Tetrahedron Lett. 34, 1871-1874.

26. Kruppa, G.H. and Beauchamp, J.L. (1986) Energetics and Structure of the 1- and 2-Adamantyl Radicals and Their Corresponding Carbonium Ions by Photoelectron Spectroscopy, J. Am. Chem. Soc. 108, 2162-2169; Walton, J.C. (1992) Bridgehead Radicals, Chem. Soc. Rev., 105-112; Tabuschi, I., Hamuro, J., and Oda, R. (1967) Free-Radical Substitution on Adamantane, J. Am. Chem. Soc. 89, 7127-7129.

27. Kochi, J.K. (1973) Free Radicals, John Wiley and Sons, Inc., New York.

28. Sawyer, D.T., Kang, C., Llobet, A., and Redman, C. (1993) Fenton Reagents (1:1 Fe $\left.{ }^{\mathrm{a}} \mathrm{L}_{\mathrm{x}} / \mathrm{HOOH}\right)$ React via $\left[\mathrm{L}_{\mathrm{x}} \mathrm{Fe}^{\mathrm{Il}} \mathrm{OOH}\left(\mathrm{BH}^{+}\right)\right](1)$ as Hydroxylases $(\mathrm{RH} \rightarrow \mathrm{ROH})$, not as Generators of Free Hydroxyl Radicals (HO'), J. Am. Chem. Soc. 115, 5817-5818 and references cited therein.

29. Yamazaki, 1. and Piette, L.H. (1991) EPR Spin-Trapping Study on the Oxidizing Species Formed in the Reaction of the Ferrous Ion with Hydrogen Peroxide, J. Am. Chem. Soc. 113, 7588-7593.

30. Bartlett, P.D., Benzing, E.P., and Pincock, R.E. (1960) Peresters. V. Di-t-butylperoxyoxalate, J. Am. Chem. Soc. 82, 1762-1768.

31. Pryor, W.A., Fuller, D.L., and Stanley, J.P. (1972) Reactivity Patterns of the Methyl Radical, J. Am. Chem. Soc. 94, 1632-1638.

32. Clark, L.J. (1962) Iron (II) Determination in the Presence of Iron (III) Using 4,7-Diphenyl-1,10phenanthroline, Anal. Chem. 34, 348-352. 